\title{
Formas de presentación pública de la persona en la red social Facebook. Notas para el análisis.
}

Julián González (jugonza@univalle.edu.co)

Profesor Titular (Estudiante de Doctorado en

Psicología)

Escuela de Comunicación Social, Facultad de Artes Integradas, Universidad del Valle.

Rocío Gómez (rociogom@univalle.edu.co) Profesora Instituto de Educación y Pedagogía - Universidad del Valle. 


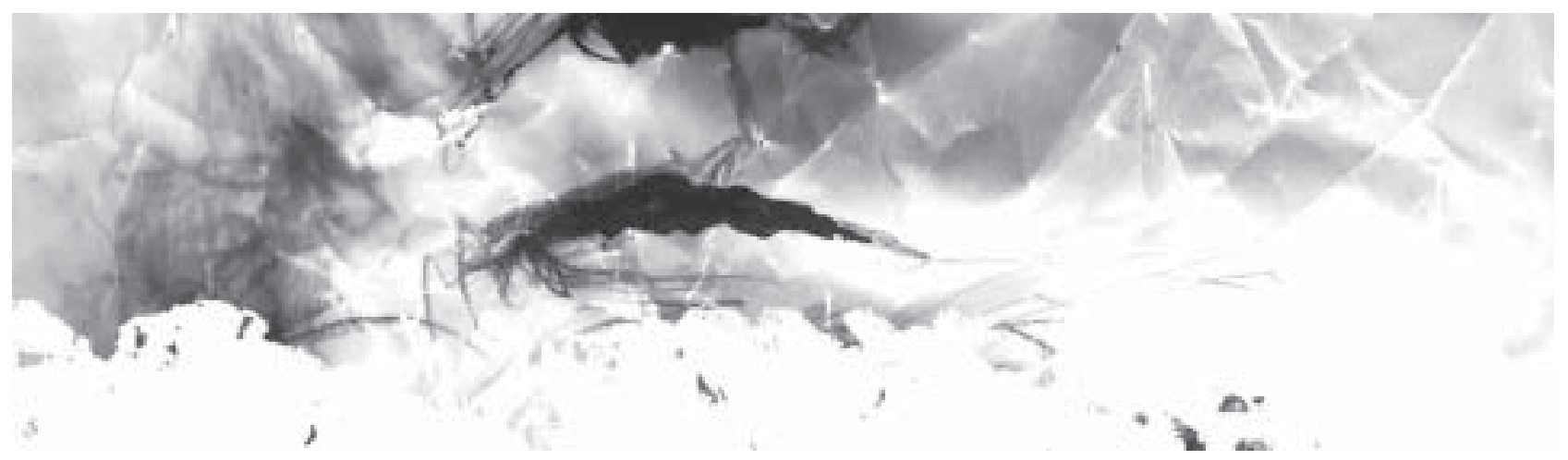

En ciencias sociales y humanidades no se acostumbra a reflexionar en qué momento los problemas se tornan intratables; prevalece una especie de optimismo metodológico, en la creencia que los estampidas combinatorias sólo se manifiestan cuando hay gran número de variables y muchos grados de

libertad. Pero [...] un sistema de 25 elementos con dos grados de libertad involucra $2^{25}$ opciones, o sea 33.554.532 alternativas; para 40 entidades (un simple tablero de 5x8) la cifra llega ya a 1.099.511.627.776. ¿Cuántos actantes y cuántos grados de libertad hay, por ejemplo, en un mito o en una composición? No cuesta mucho darse cuenta que la mayor parte de los problemas históricamente planteados en estas disciplinas se revelan intratables cuando se los mira con un poco de rigor.

(Reynoso, 2008)

\section{ntroducción.}

La web constituye un espacio privilegiado para reconocer la emergencia de nuevas formas de identidad colectiva e individual (Castells, 1999; Martín-Barbero, 2007). Para nuestro caso, representa un laboratorio espléndido en el cual advertir y apreciar cómo emergen, de manera extrema quizás, formas de presentación pública de la persona que, probablemente, en el mundo off line se ofrecen de modo más matizado y moderado, o sencillamente no existen ${ }^{1}$. Quizás es una consecuencia de la naturaleza líquida de algunas dinámicas sociales contemporáneas (Bauman, 2002) Al navegar por la marea de rostros, figuras y formas que las personas seleccionan para presentarse a sí mismos en Facebook, una de las redes sociales más usadas en Internet ${ }^{2}$, cuesta apartarse de la primera impresión que se experimenta: estamos ante una abrumadora y variopinta cantidad de rostros y una inusitada diversidad de presencias, difícilmente clasificables, aunque no se trate -por supuesto- de formas arbitrarias y aleatorias.

A modo de ejemplo, retomamos la red de vínculos de Andrea Arancibia (Chile). La forma Facebook de presentación de uno mismo en público se resume y compendia bastante bien en la siguiente agrupación de amigos de una, en principio, muy activa usuaria de esta red de encuentros (ver figura 1), en que un poco más de doscientos amigos (probablemente, mucho más de lo que podría conocer una persona en corto tiempo dentro del entorno gravitacional y 
ordinario del mundo off line) se exhiben bajo una significativa variedad de formas: desde el mapache en la fotografía 10 de la primera fila, hasta un primerísimo primer plano (un parte del rostro y el ojo) en la octava fila sexta columna; desde íconos de la industria cultural, como la gatita de la cuarta imagen en la primera fila, hasta aquellos que aún no han subido una imagen de sí y ofrecen el retrato estándar de Facebook, un perfil en blanco con fondo azul.

El presente artículo, menos que eso, constituye un documento de trabajo (en proceso de construcción) que intenta ofrecer una propuesta para clasificar este, en principio, inclasificable mercado de apariencias y presencias personales. Al examinar esta marea de presencias en Facebook toda tentativa de clasificación parece destinada a fracasar de entrada. Es Reynoso $(2004,2008)$ quien nos inspira a arriesgar esta estrategia que proponemos para clasificar las formas de presentación de sí mismo en esta red social internética; clasificación que puede resultar inesperadamente simple. Demasiado simple para ser cierto: eso puede pensarse al examinar la hipótesis que anima y atraviesa de cabo a rabo las siguientes notas.

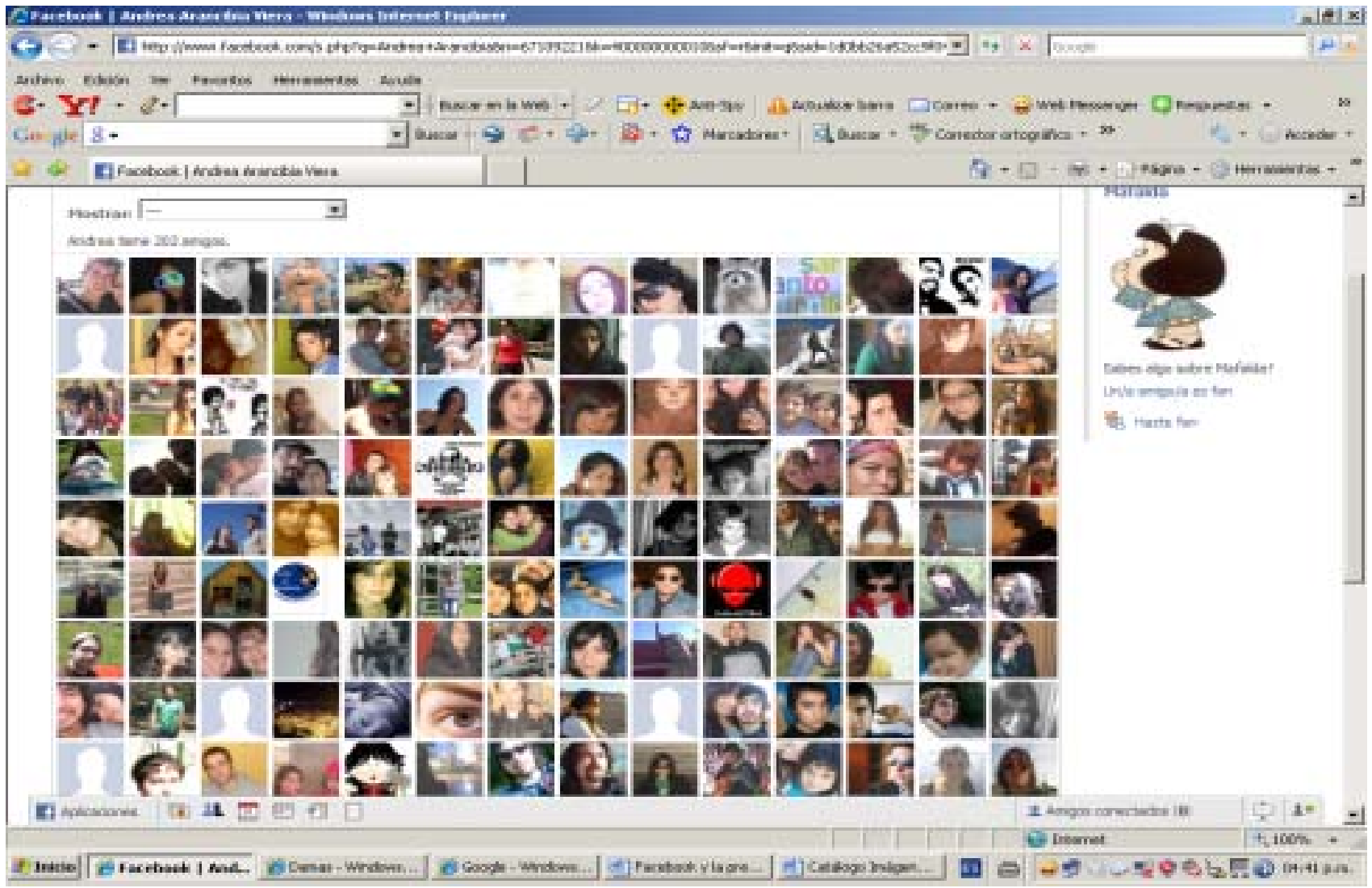

Figura 1. Red de amigos de Andrea Arancibia en Facebook.

\section{Cherchez le algorithme: Algoritmo e iteración.}

Mediante un sencillo proceso de catalogación de las imágenes usadas por los socializadores en la web para presentarse a sí mismos, conseguimos construir una taxonomía quizás un poco borgiana (esto es, a la manera de la conocida 
clasificación de animales en la enciclopedia china) de las imágenes empleadas por las personas para presentarse a sí mismos en Facebook. Esta taxonomía borgiana consideraba desde el uso de íconos de la industria cultural, hasta toda suerte de retratos más naturalistas o sobremanipulados e intervenidos, desde objetos y bienes de la vida personal del socializador (mascotas, piezas de su cuarto), hasta ilustraciones e imágenes de la industria publicitaria (bienes de consumo deseados, vg, motos, jets, relojes, marcas); desde paisajes idílicos hasta trozos y destrozos urbanos; desde ideogramas chinos que, suponemos, designan nombres, hasta puestas en escena dramáticas y teatrales (carnavalescas) de sí mismos. Sin embargo, tanto como el apreciable predominio de una amplia y variada gama de retratos, nos pareció curioso notar que otras imágenes que bien hubieran podido cumplir con suficiencia la tarea de presentar a cada cual en esa escena digital de largas y sostenidas sobreexposiciones que es Facebook, no aparecían en el catálogo: por ejemplo, huellas digitales, escarificaciones o heridas sobre la piel, radiografías.

En fin, al revisar el catálogo borgiano notamos que esta diversidad de figuras y formas podía ser reducida a un «algoritmo» bastante simple en que, mediante la iteración, se producía la diversidad real de presencias y objetos que teníamos al frente. El algoritmo es el siguiente:

La persona (P) pueden optar por presentarse a sí misma mediante un Ego (E) o un Alter-ego $(A)$, esto es una imagen que, partiendo de sí misma (su condición de persona con una historia y un lugar en el mundo social encarnado e incorporado), proyecta su presencia en la web como un vínculo de la persona consigo mismo (E) 0, por otro lado, puede proceder a proyectar su presencia en la web en términos de vínculo con otro (A). En ambos casos, la «obra» que la persona usa para presentarse a sí misma en la web es una representación: pero el procedimiento puede enfatizar en los límites estrechos de sí mismo (en particular, su cuerpo y su rostro) o en los límites más amplios (alter) de sí mismo. De esta manera tenemos que habría:
$E$
A

$\mathrm{P}$

Sin embargo, al mismo tiempo $E$ puede referir a un $E$ o un $A$; e igual $A$, puede referir a un $E$ o a un A. De esta manera, tenemos procesos de iteración que profundizan la vía ego o la vía alter, o las moderan y recombinan:

$\begin{array}{lllllll}\text { 1: } & & \text { E } & & \text { P } & & \\ \text { 2: } & \text { E } & & \text { A } & & \text { A } & \end{array}$

La anterior sería una iteración de segundo nivel, que -a la vez- puede producir una tercera, cuarta y probablemente dos o tres iteraciones más. Nuestra hipótesis es que las imágenes que representan a las personas en la red social pueden ser clasificadas y ajustadas en algunos de los niveles de esta iteración sencilla que produce diversidad.

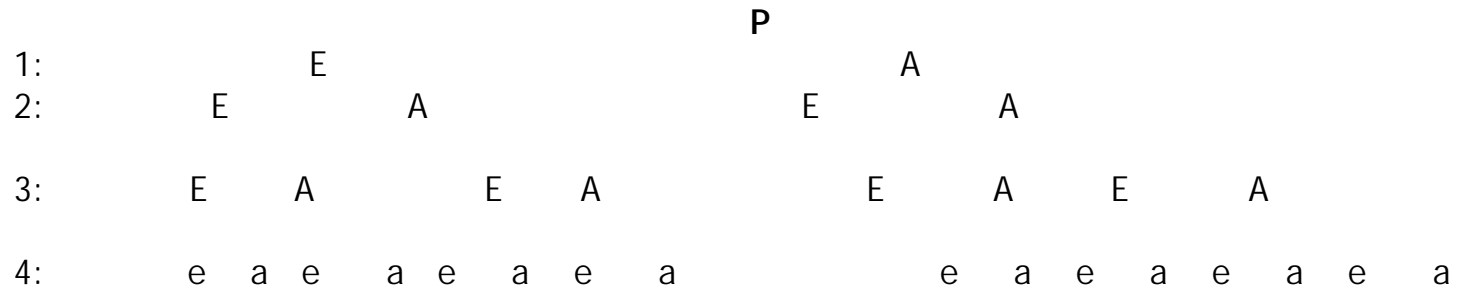


De esta manera, una iterativa selección de la vía E conduce a una representación egocéntrica fuerte (un acercamiento fuerte al ego); y la selección de la vía A conduce a una representación heterocéntrica 0 alterocentrica (alejada del ego).

Ambas representaciones exigen apelar a un objeto que es el índice del ego (yo) o del alter (otro). El recurso más usual en nuestras culturas para la encarnación representada del ego es la apelación al cuerpo propio. Y por otro lado, Io más alejado, Io más alter del ego, es una cosa, un objeto. Es decir, convengamos en que nuestras culturas tienen en las cosas la forma extrema de alteridad del ser humano, su cosificación, y tienen en el cuerpo-alma, la forma más visible de la condición humana. De esta manera, en una dinámica de iteraciones sucesivas, por la vía de extrema alteridad vamos a encontrar cosas que remiten a cosas que remiten a cosas que, en última instancia, designan a la persona. Y por la vía de extremo egocentrismo tendremos a fracciones del cuerpo que remiten a partes del cuerpo que remiten al conjunto del cuerpo que remite finalmente a la persona. Y también vamos a encontrar las variaciones intermedias, esto es, por la vía $E$, cuerpos que remiten a cosas; y por la vía $A$, objetos que remiten a Egos.

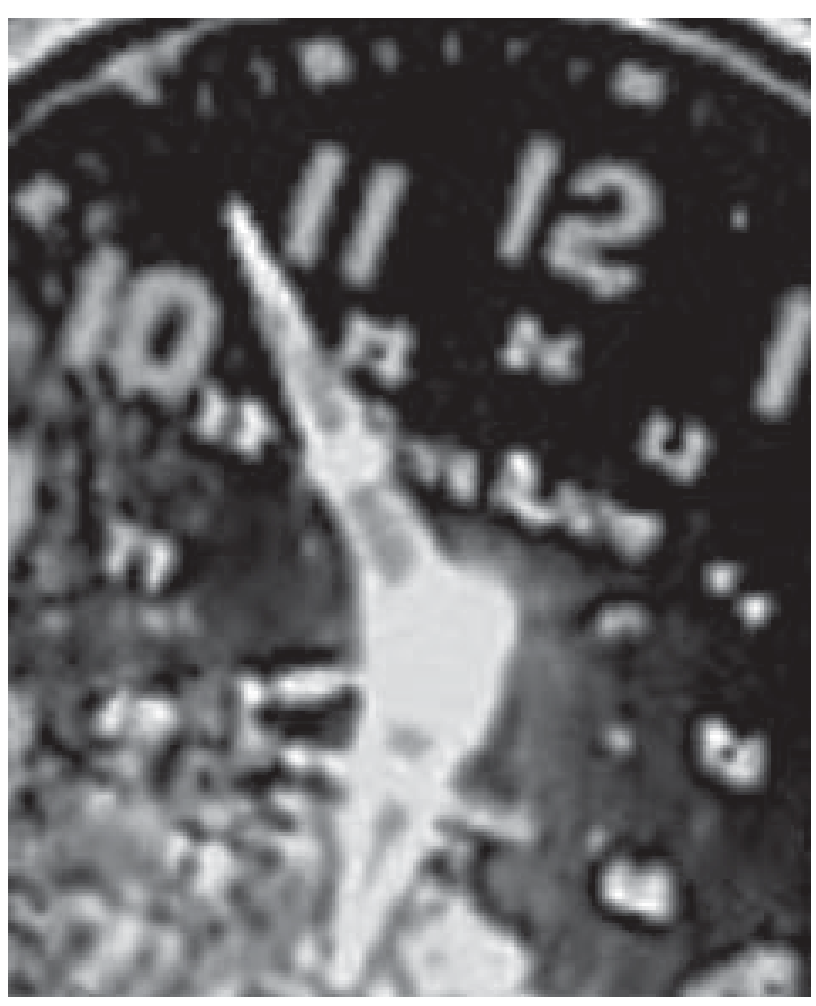

Por supuesto, hasta aquí hemos presentado una propuesta harto abstracta que podría, eventualmente, refinarse con las concepciones peircianas de primeridad, segundidad y terceridad, y las sofisticadas y refinadas distinciones en que no son dos, sino tres los fundamentos de unas combinatorias que conducirían, sin duda, una visión menos computacional y reducida de la cultura como la que aquí se ofrece hasta ahora. Pero por lo pronto, dado que nuestras pretensiones no son muy profundas, y se contentan con mostrar (no demostrar) la fuerza de un algoritmo simple y la iteración como posible dispositivo para reconocer y clasificar las formas de representación de sí mismo en una fracción del universo web como es Facebook, nos limitaremos a estos dualismos y esquematismos, y a unos pocos niveles de iteración.

Entonces, vamos a encontrar en la primera iteración aquellas representaciones que apelan a la vía E usando el cuerpo en sentido estrecho, despojado en cuanto sea posible, de toda remisión; y aquellas que apelan a la vía $A$, usando objetos cuya proximidad al Ego es más o menos clara y evidente (objetos que son un poco la huella del cuerpo). Tenemos entonces en el primer nivel de iteración los retratos de cuerpo entero (vía $E$, primera iteración) y los objetos personales (vía A, primera iteración) ${ }^{3}$.

En el siguiente nivel de iteración vamos a encontrar cuatro variantes. Variantes de la vía $\mathrm{E}$ : 1) la vía $E(E E)$ y 2) la vía $A(E A)$ del Retrato de Cuerpo Entero; y variantes de la vía $A: 3$ ) la vía $E$ $(A E)$ y 4) la vía $A(A A)$ del Objeto Personal.

- En el primer caso (1), EE, tenemos el Cuerpo entero sometido a algún tipo de close up (primeros planos): retratos del rostro, de medio cuerpo o cualquier tipo de operación de sinécdoque que pasa una porción del cuerpo por el todo, y en el que el valor de la imagen residen en que comunica trazos de la biografía e historia personal. En estas operaciones el rostro es esencial, es la unidad mínima de la operación.

- En el segundo caso (2), EA, tenemos el cuerpo entero dispuesto en un entorno de objetos y/ o personas que acompañan el cuerpo (entero o fraccionado), o el retrato despojado de toda remisión el entorno social e histórico de la persona. 


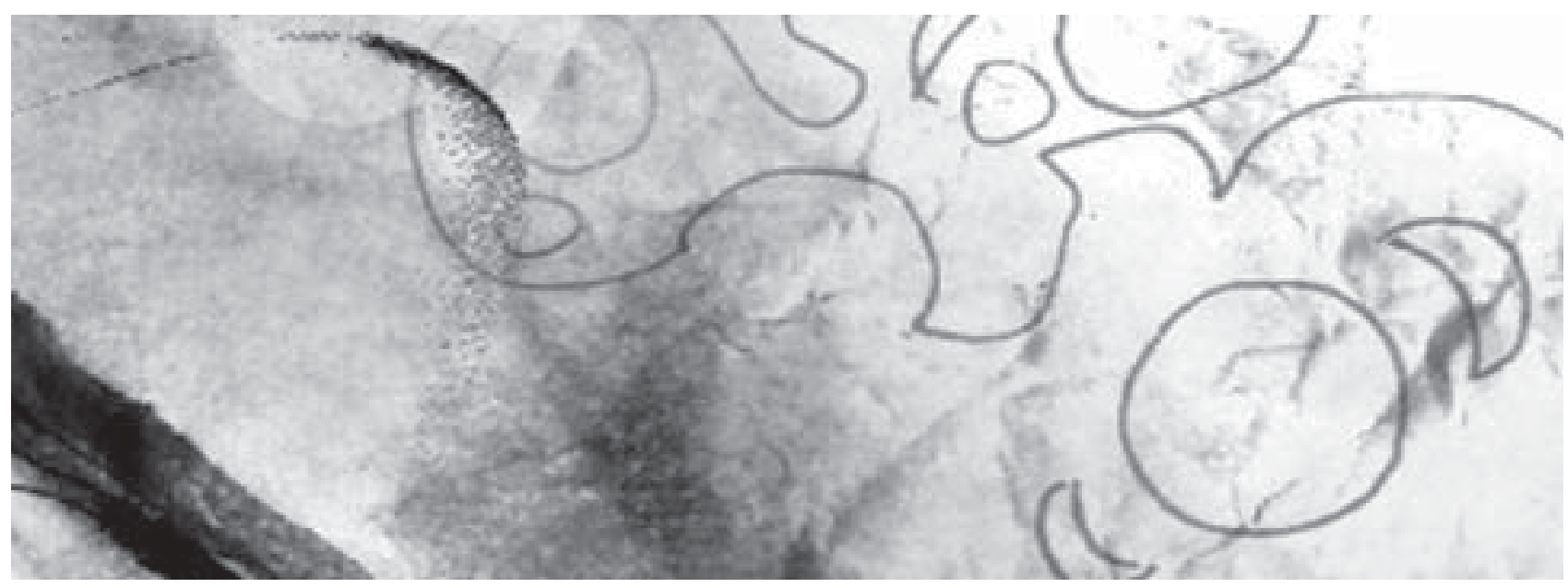

En estos casos, la puesta en escena de la imagen en sí misma procura el valor de la pieza, una suerte de aspiración a la belleza por la belleza de la imagen misma.

- Por el lado de la vía A, encontramos el tercer tipo de imágenes (3) o AE en que los objetos personales profundizan algún tipo de vínculo con $\mathrm{E}$ y tienden a señalar la conexión estrecha entre el cuerpo de la persona (relojes, cédula, la fotografía o retrato de infancia) y el objeto que la representa. En este caso los objetos, lo otro, que representa a la persona es, por decirlo menos, la huella de su paso por el mundo.

- La forma AA, cuarto tipo (4), acentúa el alejamiento respecto a la biografía de la persona y más bien profundiza el valor estético de la cosa que la representa: los paisajes que la persona ama, una toma de la ciudad en que nació, la casa en que vive transformados en postales. En la tercera iteración o tercer nivel encontraremos 8 variantes, que a su vez producirían en la cuarta iteración 16 subvariantes.

De esta manera se obtiene la siguiente distribución de tipos: hacia arriba, totalidades (cuerpo completo, objetos completos, el sujeto biográfico instalado en el mundo social, etc); y hacia abajo, fracciones. De izquierda a derecha, cuerpos densamente biográficos (en la extrema izquierda) y cosas con bajas referencias biográficas (en la extrema derecha). En el extremo inferior derecho vamos a fracciones y primeros planos de objetos como modo de representación de sí mismo; y en el extremo superior izquierdo, diferentes variaciones de retratos de cuerpo entero o de personas instaladas en su mundo social. En la parte inferior izquierda, fracciones de cuerpos y rostros con diferentes grados de sobre-esteticización y manipulación. Y en la parte superior derecha, cosas completas con significativo grado de esteticización y manipulación gráfica. (Ver tablas 1 y 2).

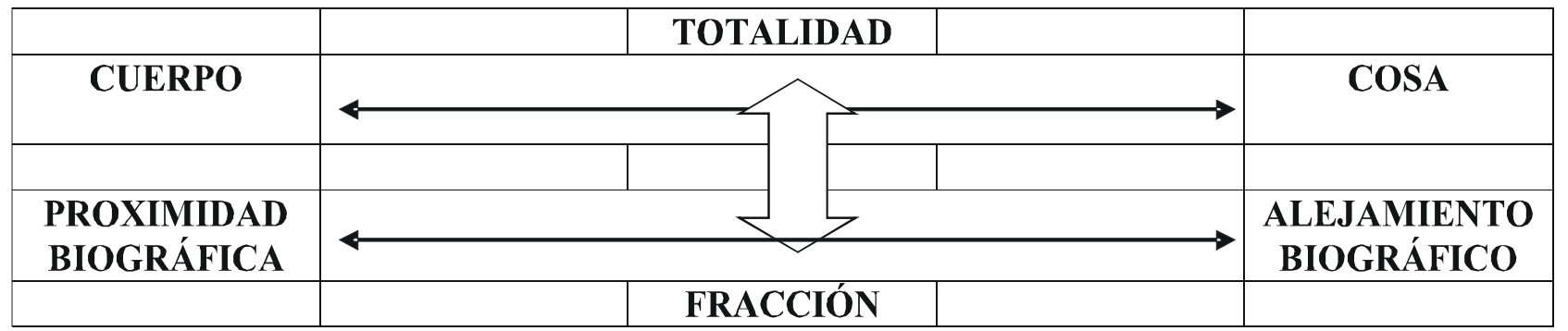

Tabla 1. Distribución de tipos y formas de representación de sí. 


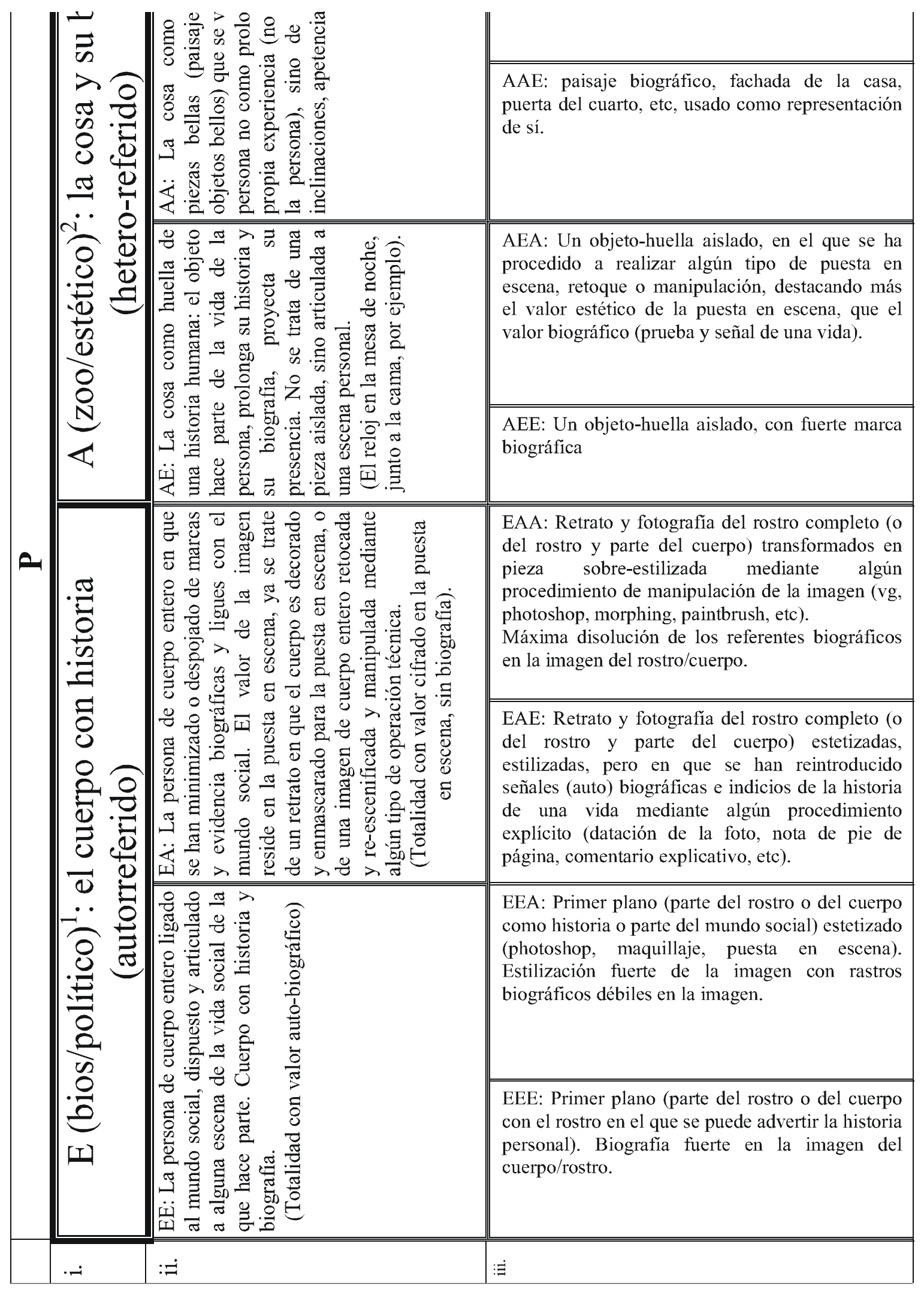


intereses, inclinaciones de la persona (postales, íconos mediáticos, etc), con algunas referencia y marcas (auto)biográficas.

AAEA: Fracción de paisaje biográfico, fachada de la casa, puerta del cuarto, etc, usado como representación de sí. Esta imagen es sobre-estetizada mediante algún tipo de procedimiento técnico.

AAEE: Fracción de paisaje biográfico, fachada de la casa, puerta del cuarto, etc, usado como representación de sí, en el que se procura alguna suerte de reescalamiento y remarcaje (auto)biográfico.

AEAA: :Fracción de un objeto-huella aislado, en el que se ha procedido a realizar algún tipo de puesta en escena, retoque o manipulación, destacando más el valor estético de la puesta en escena, que el valor biográfico (prueba y señal de una vida).

AEAE: : Fracción de un objeto-huella aislado, en el que se ha procedido a realizar algún tipo de puesta en escena, retoque o manipulación, destacando más el valor estético de la puesta en escena, que el valor biográfico (prueba y señal de una vida), en el que se introduce algún procedimiento de reescalamiento biográfico.

AEEA: Fracción de un objeto-huella aislado, con fuerte marca biográfica. Esta imagen es objeto de fuerte manipulación gráfica, estetizante. Imagen no natural.

AEEE Fracción de un objeto-huella aislado, con fuerte marca biográfica

EAAA : Fracción de EAA (el rostro o el cuerpo sobre-estetizado y estilizado). Se trata de la máxima y extrema manipulación, estilización e intervención sobre la imagen corporal o del rostro que representa a la persona. Disolución casi completa de toda referencia biográfica, indicios de la vida y coordenadas sociales de la persona.

EAAE: Fracción de EAA (el rostro o el cuerpo sobre-estetizado y estilizado). Se trata de la máxima y extrema manipulación, estilización e intervención sobre la imagen corporal o del rostro que representa a la persona. Sin embargo, a esta estilización extrema se añade alguna referencia biográfica casi externa a la imagen misma.

EAEA: Fracción de EAE (el rostro o cuerpo estilizados y re-biografiados), en la que se acentúan las marcas de biografización mediante marcas personales, firma y cualquier indicación sobre la historia de la persona tras la imagen. En esta fracción, se acentúan las operaciones de manipulación y puesta en escena.

EAEE: Fracción de EAE (el rostro o cuerpo estilizados y re-biografiados), en la que se acentúan las marcas de biografización mediante marcas personales, firma y cualquier indicación sobre la historia de la persona tras la imagen. Esta sobre-biografización no consigue disolver completamente el carácter no naturalizada (estilizado) de la imagen de base.

EEAA: Fracción de EEA (labio, ojos, cabellos, piernas, ombligo, brazos, etc, estilizados o sobreestetizados) en los que, mediante nueva manipulación visual, se consigue destacar y acentuar aún más la forma sin biografía.

EEAE: Fracción de EEA. Esa imagen con estilización fuerte con rastros biográficos débiles, sufre mediante algún tipo de procedimiento y re-escalamiento de lo biográfico- una acentuamiento de atributos identitarios, indicios idiográficos y atributos singulares o particulares de la propia vida (firma, datación, localización en el tiempo espacio, etc). La imagen no deja, sin embargo, de ser estilizada: arrugas de la piel, comisuras de los labios, perfil del rostro, en los que se advierte tanto naturalidad -

EEEA: Fracción de EEE estilizada o sobreestetizada mediante algún tipo o procedimiento de manipulación y puesta en escena (photoshop, paintbrush, flickr, etc).

EEEE: Fracción de EEE no estilizada y ni sobre-escenificada. Labios, ojos, arrugas del rostro, etc, sin ningún tipo de estilización, esto es, imagen naturalística, y en que se destacan marcas biográficas (rasgos del mundos social de la persona y su vida).

$\geq$ 
Como puede apreciarse este simple algoritmo y sus iteraciones sirve para reconocer, de manera muy esquemática y general, buena parte de las obras, textos e íconos que las personas usan para hacer la presentación pública de sí en Facebook. Por supuesto, al examinar los registros se encontrarán que menos que los tipos puros identificados en este pequeño artículo, abundan superposiciones, fusiones y yuxtaposiciones: por ejemplo, imágenes que superponen cosas y rostros (una persona que se retrata de cuerpo entero y, en donde iría su cabeza, superpone la imagen de vodka); o rostros que adquieran forma de objetos (el primer plano de un rostro vertido a una figura de cubo rubik) o presencia de variaciones de $E$ y $A$ en la misma escena.

Sin embargo, en general, se puede apreciar una mayor frecuencia de ciertos tipos que otros. A continuación se ofrece una pequeña tabla que representa la mayor 0 menor rareza de tipos en el breve estudio preliminar realizado (ver Tabla 3).

\begin{tabular}{|c|c|c|c|c|c|c|c|}
\hline \multicolumn{8}{|c|}{ Tipos } \\
\hline \multicolumn{8}{|c|}{$\mathbf{P}$} \\
\hline \multicolumn{4}{|c|}{$\mathbf{E}$} & \multicolumn{4}{|c|}{$\mathbf{A}$} \\
\hline & $\mathrm{EE}$ & \multicolumn{2}{|c|}{ EA } & \multicolumn{2}{|c|}{$\mathrm{AE}$} & \multicolumn{2}{|c|}{ AA } \\
\hline $\mathrm{EEE}$ & EEA & EAE & EAA & AEE & AEA & AAE & AAA \\
\hline EEEE EEEA & EEAE EEAA & \begin{tabular}{l|l|l} 
EAEE & EAEA \\
\end{tabular} & \begin{tabular}{|l|l|} 
EAAE & EAAA \\
\end{tabular} & 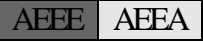 & \begin{tabular}{l|l|} 
AEAE & AEAA
\end{tabular} & $\begin{array}{l}\text { AAEE } \\
\text { AAEA }\end{array}$ & \begin{tabular}{l|l} 
AAAE & AAAA \\
\end{tabular} \\
\hline
\end{tabular}

Tabla 3 Distribución del grado de rareza o dificultad para obtener algunas de las imágenes. El arqueo de imágenes en Facebook consideró un poco más de 2000 muestras. En la figura, los colores más oscuros refieren a aquellos tipos más accesibles y fáciles de encontrar. Los recuadros más claros indican aquellos tipos de gran rareza.

Pero, adicionalmente, podría explorarse un procedimiento de monitoreo para verificar, en el tiempo, cambios y transformaciones en la composición y densidad de tipos de presentación de sí: podemos imaginarnos la selección aleatoria, cada año, de 1.000 Facebooks de la red social colombiana, para proceder a clasificar y tamizar las representaciones, y luego construir un mapa de tipos tal como se ofrece en la tabla 3. Este mapa, en el tiempo, nos permitiría ver «desplazamientos», «transformaciones», «persistencias» en algunas zonas específicas de tipos, poca densidad en otros y saturación creciente en otros. Estos cambios de un año a otro pueden entenderse como transformaciones «culturales» en las dinámicas de presentación de sí mismo en la web, emergencia o desaparición de modelos, indicios de aprendizajes y difusión de formatos.

Monitorear cambios en las sensibilidades y estéticas vívidas, en este presente progresivo (Maffesoli, 2004), de una manera más o menos estandarizada, comparable y sistemática, nos da pistas para comprender el cambio de época al que estamos asistiendo y el lugar que Internet ocupa en dichas transformaciones (Castells, 1999; Bauman, 2002; Virno, 2003;). En ese sentido, la red - siguiendo a Maffesoli (2004) - es un buen testimonio del vitalismo al que asistimos, permite reconocer algunas de las formas de reencantamiento del mundo, esto es del apetito por la vida, del inmanentismo, del gozo por las cosas. Para finalizar, ofrecemos un menú de imágenes que ilustra cada uno de los tipos planteados y expuestos. (Ver Tabla 4). Enriquecer este menú es un modo de avanzar en la propuesta de Reynoso(2008) de empezar a acostumbrarnos incorporar algunas variables que nos permitan, de un lado, aceptar la intratabilidad de los problemas sociales a los que nos enfrentamos, pero de otro lado, iniciar algunas formas precarias de modelado de datos respecto a la inevitable y fascinante inconmensurabilidad de Internet. 


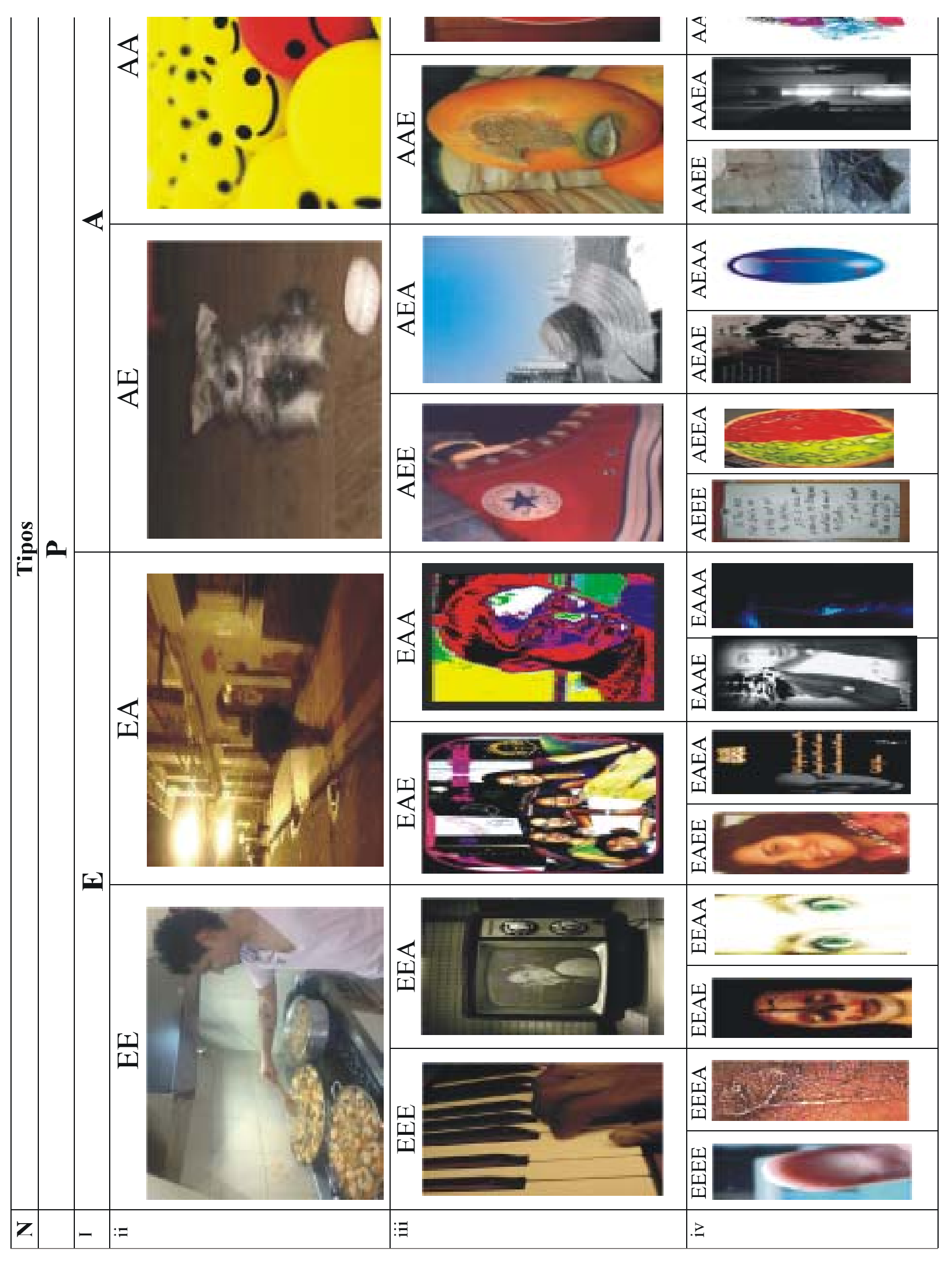

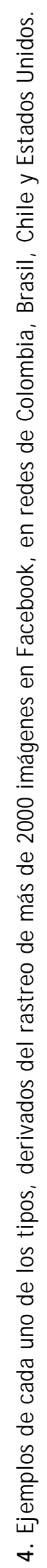




\section{Notas}

${ }^{1}$ Nótese que la web está propiciando un tipo de operación históricamente reservada a los hampones (alias) y los artistas (pseudónimo): darse un nombre. Darse un nombre, no el heredado, no el asignado por la iglesia, la familia o el Estado, es el abrebocas de darse una historia. Facebook extiende las promesas de auto-identificación: ofrece la posibilidad de inventarse una presencia, un nombre y una historia, todo junto.

${ }^{2}$ Facebook cerró en diciembre de 2008, con 132 millones de usuarios en todo el mundo y presentó un crecimiento del $153 \%$ en relación al mismo periodo de 2007. La suma de los usuarios de las principales redes sociales (Bebo, Facebook, Friendster, Hi5, MySpace, Orkut y Sónico) para América Latina en 2008, alcanzó los 29,6 millones de usuarios. Dentro de estas páginas, Facebook es la página de redes sociales que más crecimiento ha tenido en el mundo entero y tambié n en hispanoamérica (Analytics 2.0 en Español, 2009; Cincodias.com, 2009). Igualmente el crecimiento en el número de usuarios de Facebook en Colombia es uno de los más altos en el mundo y el primer país en Iberoamérica, por encima de México, España y Brasil: «en junio del 2007 cien mil personas visitaron el sitio de Facebook, frente a 1,9 millones de visitantes únicos de Colombia en junio de 2008. Facebook cuenta con 2,7 millones de colombianos inscritos» (Microstios. net, 2008). Es interesante además, destacar que al final de cada año, Google muestra estadísticas sobre las palabras más buscadas en cada país, con el fin de determinar lo que se conoce como Zeitgeist: «el espí ritu del tiempo». Se supone que el rastreo de estos términos permite hacerse a una idea general de las preocupaciones e intereses de los habitantes de cada país. Los términos se organizan en cinco categorías (Palabras Emergentes, Más Populares, Economía, Escándalos, Universidades, Los Viajes). Facebook aparece como la primera palabra más buscada en la categoría de Palabras Emergentes y como quinta en la categoría de Más Populares. A su vez Hi5 aparece como la segunda en la primera categoría y la octava en la segunda (Desarrollo y Diseño Web, 2009).

${ }^{3}$ Para facilitar la comprensión de la propuesta, reiteraremos las letras para representar de manera más simple el proceso de iteración.

${ }^{4}$ El impacto de la historia y el valor del sujeto.

${ }^{5}$ La belleza de la puesta en escena y el valor del objeto. La distinción zoo/ bios apela a la distinción clásica griega debidamente examinada por Agamben (2003) para estudiar los alcances de la biopolítica foucaultiana, entre otras, el estatuto del soberano, la figura jurídica romana del homo sacer y la nuda vida. 


\section{Bibliografía}

AGAMBEN, Giorgio (2003). Homo Sacer. El poder soberano y la nuda vida. Pretextos. Valencia. (Original en italiano, 1995)

ANALYTICS 2.0 EN ESPAÑOL (2009) «Radiografía del mercado hispano de social networks» En: http:// analytics20.org/ es/ analytics-20/ radiografía-del-mercadohispano-d-social-networks/ ojo el de la 10b.Consultado en enero de 2009.

BAUMAN, Zygmunt (2002). Modernidad Líquida. Editorial Fondo de Cultura Económica, Buenos Aires.

CASTELLS, Manuel (1999). La de la información: economía, sociedad y cultura. Volumen II: el poder de la identidad. Siglo Veintiuno Editores. México.

CINCODIAS. COM (2009). «Facebook acorrala a sus rivales al crecer un $153 \%$ en el mundo». En: http:// www. cincodias.com/ articulo/ empresas/ Facebook-acorralarivales-crecer-153-mundo/ 20080 814cdscdiemp_5/cdsemp/ Consultado en enero de 2009.

DESARROLLO Y DISEÑO WEB (2009). «Palabras más buscadas en google, 2008» En: http:// www.ingvillamizar. com/ palabras-mas-buscadas-en-google-2008/ Consultado de enero de 2009.

MAFFESOLI, Michel (2004). «Una sensibilidad primitiva». En: Estudios Sociológicos XXII: 66, 2004.

MARTIN BARBERO, J esús (2007) «Reconfiguraciones de lo público y nuevas ciudadanías». En: GONZÁLEZ, J orge Enrique (Ed) Ciudadanía y Cultura. Tercer Mundo Editores. Bogotá.

MICROSITIOS. NET (2008) «Colombia es número uno en Facebook entre los países de habla hispana». En: http:/ / www. micrositios. net/ index. php?idcategoria $=677$ Consultado en enero de 2009.

REYNOSO Carlos (2004) «Herramientas de complejidad y caos para las ciencias sociales». En: Boletín de Antropología Americana No 40. Instituto Panamericano de Historia y Geografía. México.

REYNOSO Carlos (2008) «Diseño en artes visuales y sonoras con metaheurísticas evolutivas». Septiembre de 2008. En: http:// carlosreynoso.com.ar/archivos/ arte-y-metaheuristicas. pdf.

VIRNO, Paolo (2003). Gramáticas de la multitud. Para un análisis de las formas de vida contemporánea. En: http:// traficantes. net/ index. php/trafis/ editorial/ catalogo/coleccion_mapas/gramatica de la multitud para una analisis de las formas de vida contemporaneas. 